\title{
BMJ Open Calcium channel blockers and cancer: a risk analysis using the UK Clinical Practice Research Datalink (CPRD)
}

\author{
Lamiae Grimaldi-Bensouda, ${ }^{1,2}$ Olaf Klungel, ${ }^{3}$ Xavier Kurz, ${ }^{4}$ Mark C H de Groot ${ }^{3}$ \\ Ana S Maciel Afonso, ${ }^{3}$ Marie L de Bruin, ${ }^{3}$ Robert Reynolds, ${ }^{5,6}$ Michel Rossignol ${ }^{7}$
}

To cite: GrimaldiBensouda L, Klungel 0 , Kurz X, et al. Calcium channel blockers and cancer: a risk analysis using the UK Clinical Practice Research Datalink (CPRD). BMJ Open 2016:6:e009147.

doi:10.1136/bmjopen-2015009147

- Prepublication history for this paper is available online. To view these files please visit the journal online (http://dx.doi.org/10.1136/ bmjopen-2015-009147)

Received 29 July 2015 Revised 25 September 2015 Accepted 5 October 2015

\section{CrossMark}

For numbered affiliations see end of article.

Correspondence to Dr Lamiae GrimaldiBensouda;

Lamiae.Grimaldi@la-ser.com

\section{ABSTRACT}

Objective: The evidence of an association between calcium channel blockers (CCBs) and cancer is conflicting. The objective of the present study was to evaluate the risk of cancer (all, breast, prostate and colon cancers) in association with exposure to CCB. Methods: This is a population-based cohort study in patients exposed to CCBs from across the UK, using two comparison cohorts: (1) patients with no exposure to CCB (non-CCB) matched on age and gender and (2) unmatched patients unexposed to $C C B$ and at least one other antihypertensive (AHT) prescription. Cancer incidence rates computed in the exposed and the two unexposed groups were compared using HRs and 95\% Cls obtained from multivariate Cox regression analyses.

Results: Overall, 150750,557931 and 156966 patients were included, respectively, in the CCB, nonCCB and AHT cohorts. Crude cancer incidence rates per 1000 person-years were $16.51,15.75$ and 10.62 for the three cohorts, respectively. Adjusted HRs (Cl) for all cancers comparing CCB, non-CCB and AHT cohorts were $0.88(0.86$ to 0.89$)$ and 1.01 (0.98 to 1.04), respectively. Compared to the AHT cohort, adjusted $\mathrm{HRs}(\mathrm{Cl})$ for breast, prostate and colon cancer for the CCB cohort were 0.95 (0.87 to 1.04), 1.07 (0.98 to 1.16) and 0.89 (0.81 to 0.98$)$, respectively. Analyses by duration of exposure to CCB did not show excess risk.

Conclusions: This large population-based study provides strong evidence that CCB use is not associated with an increased risk of cancer. The analyses yielded robust results across all types of cancer and different durations of exposure to CCBs.

\section{INTRODUCTION}

Calcium channel blockers (CCBs) are a diverse group of medicines that are widely used to treat cardiovascular diseases including hypertension and angina. Antihypertensive (AHT) drugs are the most commonly prescribed class of medicines in the USA, with 97.9 million CCB prescriptions issued in that country during $2010 ;{ }^{1}$ in

\section{Strengths and limitations of this study}

- This is a large-scale population-based study investigating differences in cancer risk between calcium channel blocker (CCB), non-CCB and non-CCB antihypertensive drugs users.

- Extended analyses included specific cancer locations and cumulative length of exposure.

- The study spanned a 14-year period (19962009) and required patients to have at least 2 years of follow-up data.

- Exposure variables are unlikely to introduce bias considering physicians collected from Clinical Practice Research Datalink (CPRD) data while unaware of the hypothesis being tested in this analysis.

- The results of this study might not apply directly to socially and ethnically diverse populations not included in the CPRD network of physicians, and generalisation therefore must be made cautiously.

Europe, hypertension is one of the most common interventions in primary care, and CCBs are a first-line treatment for this. ${ }^{2}$ However, it has been suggested that CCBs may interfere with apoptosis, leading to an increased potential for abnormal cell proliferation and tumour growth. Epidemiological studies investigating the association between CCBs and cancer vary in terms of patients' characteristics, design, outcome variables and geographic location, the compound of which complicates assessment and synthesis of results across studies. While several studies showed an association between CCB use and an increased risk for all forms of cancer ${ }^{4} 5$ and breast cancer, ${ }^{6-9}$ others reported no risk. ${ }^{10-15}$

Electronic healthcare databases used previously to investigate potential associations between CCB use and cancer can offer several advantages over primary data collection methods, particularly large sampling and limiting selection bias. ${ }^{16}$ We used the 
Clinical Practice Research Datalink (CPRD; formally known as the General Practice Research Database), the world's largest database of anonymised clinical records. The primary objective of the present study was to investigate the potential association between CCB use and risk for all types of cancer, using data compiled from the CPRD between 1996 and 2009. Secondary objectives were to investigate the association between CCB and colon, breast and prostate cancers. This study was part of the Pharmacoepidemiological Research on Outcomes (PROTECT) project, the main goal of which is to strengthen the monitoring of the benefit-risk balance of medicines in Europe. ${ }^{17}$

\section{METHODS}

\section{Data source}

We conducted a population-based cohort study using data from the CPRD. Managed by the British Department of Health, the CPRD contains over 5 million active patient records (over 13 million overall) from approximately 650 primary care practices across the UK. Sets of CPRD data have been routinely validated, including diagnosis ${ }^{18-20}$ and drug exposure data. $^{21} 22$ This information was linked to data from the National Cancer Registration System (NCRS), which currently includes 11 cancer registries, each with populations of between 1.65 and 13.8 million patients. ${ }^{23}$ Details were collected from a variety of sources including public and private hospitals, cancer centres, hospices, cancer screening programmes, other cancer registers, general practices, nursing homes, death certificates and the Hospital Episode Statistics. The NCRS contains data from patients across the whole of the UK, but the current study only used data from the English and Scottish Cancer Registration regions.

\section{Study population}

The study population included all patients aged 1879 years in the CPRD-with linkable NCRS data for the study period between 1 January 1996 and 31 December 2009-identified as having visited a general practitioner at least once during that period, 2 years of primary care history (up to standard) and at least 1 year of computerised prescription history.

Patients with at least one CCB prescription between 1996 and 2009 (CCB exposure cohort) were compared against those in two comparison cohorts. The first comparison cohort included all patients without CCB prescriptions between 1996 and 2009 (non-CCB cohort). Patients in the CCB cohort were matched by age and sex to a maximum of four patients in the non-CCB cohort. The second comparison cohort was a subset of the first, including unmatched patients with no CCB prescriptions but who had been prescribed at least one other AHT drug from 1996 to 2009 (AHT cohort).

Members of each of the three cohorts were observed for the occurrence of cancer starting 6 months after their index date, defined as the date of first CCB use (CCB cohort), the date of first AHT drug use (AHT cohort) and, for the non-CCB cohort, the same date as first CCB use for their matched CCB user. Patients with any record of cancer prior to the index date were excluded from all three cohorts. Each patient was followed until the earliest date of one of the following was reached (whichever came first): cancer diagnosis, patient death, 80 years of age, completion of data collection, or practice left the CPRD database.

\section{Exposure definition}

Drug codes used to identify CCB and AHT drug use were based on the British National Formulary (BNF). Patients were considered to be exposed to a drug if they had been prescribed at least one prescription between 1996 and 2009. Exposure to CCB drugs was categorised into three subgroups: CCBs with direct cardiac effects (diltiazem, gallopamil and verapamil; Anatomical Therapeutic Chemical (ATC) codes $=$ C08D), nonselective CCBs (bepridil, fendiline, lidoflazine and perhexiline; ATC codes $=\mathrm{C} 08 \mathrm{E}$ ) and vascular selective $\mathrm{CCBs}$ (all other CCBs; ATC codes=C08C). Duration of exposure to CCBs was calculated as the total cumulative exposure derived from the total amount resulting from the defined daily dose (DDD), the number of prescriptions and the period covered by the prescriptions (package size). Exposure to the following AHT drugs was considered for inclusion into the AHT cohort: diuretics, $\beta$-blockers, ACE inhibitors, adrenergic neuron blockers, $\alpha$-blockers, AHT vasodilators, centrally acting AHT drugs, angiotensin II antagonists and renin inhibitors. These were chosen because there is no previous evidence linking them to an increased risk of cancer incidence.

\section{Outcome definition}

Information on cancer outcomes was extracted from the UK NCRS, which includes 11 regional registries. Cancer diagnoses were identified using READ codes and International Classification of Diseases, 10th Revision (ICD-10) codes, and included all primary and multiple sites malignant neoplasms (corresponding to ICD-10 codes $\mathrm{C} 00-\mathrm{C} 97$ ), and carcinoma in situ (corresponding to ICD-10 codes D00-D09) of a known origin. Specific analyses were performed on the following three types of cancer, breast (ICD-10 code C50), prostate (ICD-10 code C61) and colon (ICD-10 code C18). Benign neoplasms (corresponding to ICD-10 codes D10-D36) and neoplasms of uncertain or unknown origin (corresponding to ICD-10 codes D37-D48) were excluded from the analyses.

\section{Statistical analyses}

Crude cancer incidence rates for all three cohorts were calculated as the number of cancer occurrences per 1000 person-years. The CCB cohort was compared to both, the non-CCB and AHT cohorts, with regard to 
cancer (all types). Cox regression models were conducted to estimate the crude and multivariable adjusted relative risk by calculating HRs and 95\% CIs of cancer in relation to drug exposure (ever vs never exposed). Potential confounding factors in the relation between cancer and CCB exposure were accounted for in multivariable regression models and included: age at index date and sex (matching variables in the comparison with the non-CCB cohort), smoking status, body mass index (BMI), alcohol consumption, diabetes, hypertension, arrhythmia, angina, or heart failure, as well as the use of statins or aspirin. These factors were chosen based on previous findings linking the variables with an increased risk of cancer. For the AHT cohort, separate analyses were performed for colon cancer, breast cancer in women and prostate cancer in men. Additional analyses were also conducted using the AHT cohort to account for switching drug exposure, with models stratified according to the duration of cumulative exposure to drugs $(0-5,5-10$ and $>10$ years). All analyses were conducted using SAS software V.9.2 (SAS Institute, Inc, North Carolina, USA). The study protocol was registered at the ENCePP electronic register of studies (http:// www.encepp.eu/encepp/studiesDatabase.jsp).

\section{RESULTS}

\section{Population characteristics}

A total of 150750 patients were included in the CCB cohort, 557931 in the non-CCB cohort and 156966 in the AHT cohort. The proportion of males and females in the CCB cohort was similar to the non-CCB cohort (matching variable) but with slightly more males when compared to the AHT cohort (respectively, $49.7 \%$ and $46.0 \%$, table 1). However, participants in the CCB cohort were 10 years older than participants in the AHT cohort (respectively, 61.5 and 51.4 years), with a higher prevalence of overweight people with diabetes, hypertension or angina than in the non-CCB and AHT cohorts. Participants in the CCB cohort were also more likely to have been prescribed statins or aspirin than the other two cohorts.

\section{CCB and risk of any cancer}

Crude cancer rates were highest in the $\mathrm{CCB}$ cohort, with $16.51 / 1000$ person-years, followed by the non-CCB cohort, with $15.75 / 1000$ person-years and the AHT cohort, with 10.62/1000 person-years (table 2). In adjusted multivariate analyses, CCB exposure was not associated with an increased risk for any type of cancer when compared to the AHT cohort (HR 1.01; CI 0.98 to 1.04). This lack of association remained unchanged when the analysis was restricted to vascular-selective CCBs (HR 1.00; CI 0.98 to 1.03) or CCBs with direct cardiac effects (HR 0.96; CI 0.88 to 1.05). The number of patients was insufficient to perform a separate analysis on non-selective CCBs. Conversely, all types of cancer were slightly less frequent in patients who were exposed to CCBs compared to those in the non-CCB cohort (HR 0.88 ; CI 0.86 to 0.89 ).

\section{Risk of breast, prostate and colon cancer}

Consistent with results for all cancers, breast and prostate cancer rates (crude rates) were higher in the $\mathrm{CCB}$ cohort than in the AHT cohort-respectively, 3.05 and 2.32 cases per 1000 person-years for breast cancer, and 4.10 and 2.50 cases per 1000 person-years for prostate cancer (table 3). In adjusted multivariate analyses, no differences were found for relative risk of breast cancer (HR 0.95; CI 0.87 to 1.04) or prostate cancer (HR 1.07; CI 0.98 to 1.16 ) between the CCB and AHT cohorts. In contrast, colon cancer rates were lower for CCB-exposed patients compared with those of the AHT cohort (0.92 compared with $1.41 / 1000$ person-years). CCB exposure also showed a small but significant protective effect for prostate cancer compared to the AHT cohort (HR 0.89; CI 0.81 to 0.89 ).

\section{Risk of cancer and duration of exposure to CCBs}

Cancer rates were higher in the CCB cohort than in the AHT cohort regardless of duration of drug exposure (ie, all durations), although the difference between rates decreased as the cumulative exposure increased (<5 years: 25.9 compared with $13.8 ; 5-10$ years: 10.53 compared with $8.75 ;>10$ years: 4.59 compared with 3.08 ; table 4). There was no significant evidence of a relation between cancer risk and increasing duration of cumulative CCB exposure as opposed to the AHT cohort. In fact, patients exposed to CCBs up to 5 years were less likely to develop any type of cancer (all cancers) than patients exposed to all other AHT drugs for the same duration of treatment (HR 0.88; CI 0.85 to 0.91 ). No difference in cancer risk between CCB and AHT cohorts was found for participants prescribed these drugs for a total of 5-10 years (HR 0.98; CI 0.93 to 1.04 ) or beyond 10 years (HR 1.11; CI 0.98 to 1.27). Duration of exposure to CCB drugs was also specifically examined in relation to the risk of breast cancer. These results did not differ from those listed above, with HR that decreased below unity with increasing duration of exposure.

\section{DISCUSSION}

\section{Summary of findings}

This population-based cohort study among British adults found that exposure to CCBs was not associated with an increased risk of cancer, all types combined. On the contrary, for patients taking CCBs for $<5$ years, our results suggest CCB exposure to be associated with a lower risk for any of the types of cancer studied. This study also found no difference in cancer risk for patients exposed to CCBs compared to those exposed to the most commonly used types of AHT drugs. This finding was consistent across all types of cancer, as well as for breast and prostate cancers. Patients exposed to CCBs were at lower risk of colon cancer than those exposed to other AHT 
Table 1 Population characteristics of the calcium channel blocker (CCB), non-CCB and non-CCB antihypertensive (AHT) drugs cohorts

\begin{tabular}{|c|c|c|c|}
\hline Variables & CCB cohort n (\%) & Non-CCB cohort n (\%) & AHT cohort $n(\%)$ \\
\hline Total sample & 150750 & 557931 & 156966 \\
\hline \multicolumn{4}{|l|}{ Age (index date, years) } \\
\hline Mean (SD) & $61.5(11.5)$ & $60.1(12.1)$ & $51.4(15.4)$ \\
\hline \multicolumn{4}{|l|}{ Gender } \\
\hline Male & 74956 (49.7) & $281575(50.5)$ & $72269(46.0)$ \\
\hline Female & $75794(50.3)$ & $276356(49.5)$ & $84697(54.0)$ \\
\hline \multicolumn{4}{|l|}{ BMI $\left(\mathrm{kg} / \mathrm{m}^{2}\right)$} \\
\hline$\geq 30$ & $42683(28.3)$ & $78158(14.0)$ & $32198(20.5)$ \\
\hline $25-29$ & 50251 (33.3) & $149397(26.8)$ & $44220(28.2)$ \\
\hline$<24$ & $32749(21.7)$ & $159215(28.5)$ & $45681(29.1)$ \\
\hline Missing* & 25067 (16.6) & $171161(30.7)$ & 34867 (22.2) \\
\hline \multicolumn{4}{|l|}{ Smoking } \\
\hline Ever & $77220(51.2)$ & $243112(43.6)$ & $76252(48.6)$ \\
\hline Never & $67540(44.8)$ & $250893(45.0)$ & $70171(44.7)$ \\
\hline Missing* & $5990(4.0)$ & $63926(11.5)$ & $10543(6.7)$ \\
\hline \multicolumn{4}{|l|}{ Alcohol use } \\
\hline Current (high or increasing) & $9723(6.4)$ & $22945(4.1)$ & $8767(5.6)$ \\
\hline Current (low) & 59050 (39.2) & 199667 (35.8) & $61580(39.2)$ \\
\hline Current (unknown) & $27290(18.1)$ & $85252(15.3)$ & $26802(17.1)$ \\
\hline Former drinker & $2438(1.6)$ & $6899(1.2)$ & $2132(1.4)$ \\
\hline Non-drinker & $19887(13.2)$ & $57850(10.4)$ & $16876(10.8)$ \\
\hline Missing ${ }^{*}$ & $32362(21.5)$ & $185318(33.2)$ & 40809 (26.0) \\
\hline \multicolumn{4}{|c|}{ Diagnosis of diabetes before or at baseline } \\
\hline Yes & $18287(12.1)$ & $28305(5.1)$ & $13648(8.7)$ \\
\hline No & 132463 (87.9) & 529626 (94.9) & $143318(91.3)$ \\
\hline \multicolumn{4}{|c|}{ Hypertension before or at baseline } \\
\hline Yes & $111022(73.6)$ & 74033 (13.3) & $45724(29.1)$ \\
\hline No & $39728(26.4)$ & $483898(86.7)$ & $111242(70.9)$ \\
\hline \multicolumn{4}{|l|}{ Angina before or at baseline } \\
\hline Yes & $13637(9.0)$ & $17531(3.1)$ & $4887(3.1)$ \\
\hline No & $137113(91.0)$ & $540400(96.9)$ & 152079 (96.9) \\
\hline \multicolumn{4}{|l|}{ Arrhythmia before or at baseline } \\
\hline Yes & $6873(4.6)$ & $13144(2.4)$ & 5907 (3.8) \\
\hline No & $143877(95.4)$ & $544787(97.6)$ & 151059 (96.2) \\
\hline \multicolumn{4}{|c|}{ Heart failure before or at baseline } \\
\hline Yes & $2392(1.6)$ & $8322(1.5)$ & $2277(1.5)$ \\
\hline No & $148358(98.4)$ & $549609(98.5)$ & $154689(98.5)$ \\
\hline \multicolumn{4}{|c|}{ Statin use within 1 year of or at baseline } \\
\hline Yes & $42801(28.4)$ & $58417(10.5)$ & $26360(16.8)$ \\
\hline No & $107949(71.6)$ & 499514 (89.5) & $130606(83.2)$ \\
\hline \multicolumn{4}{|c|}{ Aspirin use within 1 year of or at baseline } \\
\hline Yes & 37025 (24.6) & $49949(9.0)$ & $24050(15.3)$ \\
\hline No & $113725(75.4)$ & $507982(91.0)$ & $132916(84.7)$ \\
\hline
\end{tabular}

drugs. Our study also found no differences between categories of CCB drugs (vascular and cardiac-selective) and no increased risk of cancer with increasing duration of exposure to CCBs.

\section{Comparisons with current evidence}

Only a few follow-up studies showed findings different to ours, reporting an increased risk for all types of cancer ${ }^{4}{ }^{24}$ or breast cancer. ${ }^{6} 8925$ An early cohort study by Pahor et a $\tilde{l}$ reported that CCB use was associated with an overall twofold increase in cancer risk in
750 elderly individuals with hypertension. A repeated analysis using the same cohort, but a different inclusion criteria, found that the risk of developing cancer increased by approximately 1.7 times for CCB users compared with non-users. ${ }^{4}$ Fitzpatrick $e t$ at found a 2.6-fold increased risk for breast cancer in CCB users compared with non-CCB users in their study of 3198 women aged 65 years or older. In the majority of studies, the strength of this association appeared to be dependent on daily dosage or cumulative dose, ranging from no association in users of low dosages to a twofold (or possibly higher) 
Table 2 Risk of all types of cancer in the calcium channel blocker (CCB) cohort compared to the non-CCB and the non-CCB antihypertensive (AHT) drugs cohorts

\begin{tabular}{|c|c|c|c|c|c|c|c|}
\hline \multirow[b]{2}{*}{ Cohort } & \multirow[b]{2}{*}{$\begin{array}{l}\text { Number of } \\
\text { cancers }\end{array}$} & \multirow[b]{2}{*}{$\begin{array}{l}\text { Number of } \\
\text { person-years }\end{array}$} & \multirow{2}{*}{$\begin{array}{l}\text { Cancer incidence } \\
\text { rates (per } 1000 \\
\text { person-years) }\end{array}$} & \multicolumn{2}{|l|}{ CCB vs non-CCB } & \multirow{2}{*}{$\begin{array}{l}\text { CCB vs AHT } \\
\text { Crude HR } \\
(95 \% \mathrm{Cl}) \\
\end{array}$} & \multirow[b]{2}{*}{ Adjusted HR } \\
\hline & & & & $\begin{array}{l}\text { Crude HR } \\
(95 \% \mathrm{Cl})\end{array}$ & Adjusted HR & & \\
\hline $\mathrm{CCB}$ & 14588 & 303 & 16.51 & 1.03 & $0.88(0.86 \text { to } 0.89)^{\star}$ & $1.56(1.53$ to 1.61$)$ & 1.01 (0.98 to 1.04$)$ \\
\hline Non-CCB & 43992 & 2792948 & 15.75 & 1.00 (reference) & 1.00 (reference) & - & - \\
\hline AHT & 9754 & 918801 & 10.62 & - & - & 1.00 (reference) & 1.00 (reference) \\
\hline
\end{tabular}

${ }^{*} p<0.001$. HR obtained from multivariate Cox proportional hazard analyses including age at index date, gender, smoking status, body mass index, alcohol consumption, diagnoses of diabetes, hypertension, arrhythmia, angina or heart failure, and use of statins or aspirin.

increased risk when higher dosages were used. Our study found no difference in the strength of the association when considering the cumulative exposure to drugs over time; and an association was also not evident until at least 2-3 years after exposure. Furthermore, cancer risk was primarily highest for exposure to verapamil, ${ }^{24}$ while no such relation was reported for diltiazem, and no consistent associations were shown for specific cancer sites or histological types. ${ }^{25}$ However, in contrast to our study, a paper by Li $e t a l^{8}$ reported that the use of particular types of AHT medicines, including immediate-release CCBs and certain diuretics, was associated with a modest increased risk of breast cancer among 975 women aged 65-79 years. Davis and Mirick ${ }^{9}$ also found that breast cancer risk was not associated with the use of $\beta$-blockers.

Results from a large number of observational studies are consistent with our finding that long-term CCB use is not associated with cancer risk. ${ }^{11}{ }^{14}{ }^{26-30}$ For example, multiple case-control studies investigating the risk of developing cancer among patients with hypertension treated with CCBs or other AHTs have also found a similar risk for malignancy among users and non-users

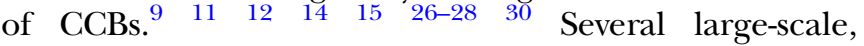
population-based cohort studies that took place in Denmark, ${ }^{10} 3132$ the USA, ${ }^{13} 33$ the $\mathrm{UK}^{34}$ and Europe,${ }^{35}$ also found no evidence for an association between CCB use and cancer. Limitations of these studies included the use of self-reported exposure data ${ }^{13} 35$ and lack of covariate information on relevant confounders, such as smoking, BMI and alcohol use. ${ }^{10} 313234$ Cohen $e t a l^{33}$ carried out three successive interviews in over 3500 individuals from North Carolina, USA, aged 65-105 years. After adjusting for baseline and time-dependent covariates such as race, diabetes, blood pressure, CCB dose, $\mathrm{CCB}$ class and length of follow-up, cancer risk was similar between CCB users and non-users. Our study differed from the study by Cohen $e t a \hat{l}^{33}$ in several respects, notably, the ethnic diversity of our study population, the time period covered (more recent) and the definition of CCB user status (first-time users). González-Pérez $e t a l^{34}$ also used data from the CPRD to investigate the association between breast cancer and AHT drugs, specifically captopril, and also found that breast cancer incidence was similar for users and non-users. They also found that captopril was not associated with a reduced risk of breast cancer. Trenkwalder et $a l^{35}$ investigated the use of CCBs and incidence of fatal and non-fatal cancer in a 3-year follow-up study of over 1000 elderly patients. Similarly, they found that CCB use did not increase the risk of fatal or non-fatal cancer in their elderly central European population. The findings from the Danish cohort studies also agree with our findings related to specific cancer types. For example, the study by Fryzek et $a l,{ }^{10}$ including almost 50000 Danish women, found no evidence that AHT drug use (including CCBs) was related to breast cancer. Olsen et $a l^{31}$ reported no increased risk of colon cancer between CCB users as compared to non-users in a Danish study of almost 18000 patients. Our findings differ from recently published findings by Li et $a l^{1}{ }^{1}$ who found that long-term use of CCB was particularly associated with breast cancer.

\begin{tabular}{|c|c|c|c|c|c|c|}
\hline & \multicolumn{2}{|c|}{ Breast cancer (women only) } & \multicolumn{2}{|c|}{ Prostate cancer (men only) } & \multicolumn{2}{|l|}{ Colon cancer } \\
\hline & CCB cohort & AHT cohort & CCB cohort & AHT cohort & CCB cohort & AHT cohort \\
\hline $\begin{array}{l}\text { Cancer rates (crude } \\
\text { per } 1000 \\
\text { person-years) }\end{array}$ & 3.05 & 2.32 & 4.10 & 2.50 & 1.41 & 0.92 \\
\hline Number of cancers & 1397 & 1194 & 1753 & 1014 & 1249 & 849 \\
\hline $\begin{array}{l}\text { Number of } \\
\text { person-years }\end{array}$ & 457417 & 514400 & 427654 & 404833 & 885070 & 919233 \\
\hline Crude HR (95\% Cl) & $1.33(1.23$ to 1.43$)$ & 1.00 (reference) & 1.64 (1.52 to 1.78$)$ & 1.00 (reference) & 1.54 (1.41 to 1.68$)$ & 1.00 (reference) \\
\hline $\begin{array}{l}\text { Adjusted HR } \\
(95 \% \mathrm{Cl})\end{array}$ & $0.95(0.87$ to 1.04$)$ & 1.00 (reference) & 1.07 (0.98 to 1.16$)$ & 1.00 (reference) & $0.89(0.81 \text { to } 0.98)^{\star}$ & 1.00 (reference) \\
\hline
\end{tabular}




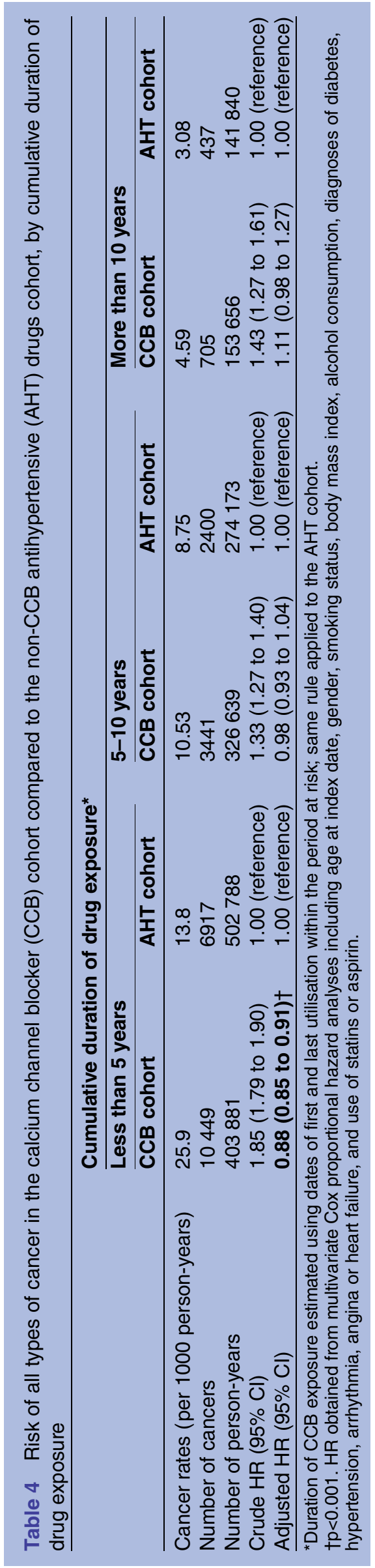

Strengths and limitations

To the best of our knowledge, ours is the first large-scale population-based study to investigate differences in cancer risk between $\mathrm{CCB}$, non-CCB and non-CCB AHT drug users. Extended analyses included specific cancer locations and cumulative length of exposure. Our study spanned a 14-year period (1996-2009) and required patients to have at least 2 years of follow-up data. The results of this study do not apply directly to populations not included in the CPRD network of physicians. However, this large, socially and ethnically diverse study population is likely to be representative of the British population, for the CPRD contains data from primary care practices across the whole of the UK. To maximise internal validity, we selected two different populations of CCB non-users for comparison. We hypothesised that patients exposed to AHT drugs other than CCBs represented the best choice; however, this population turned out to be much younger than that of CCB users. Multivariate analyses adjusted for these age differences, and other potential confounders for the association between cancer and CCB use, were performed. This was possible due to the breadth of information collected in the CPRD. Finally, exposure variables as recorded by physicians are unlikely to be biased because CPRD data has been shown to be valid and reliable, and collected while unaware of the hypothesis being tested in this analysis. ${ }^{22}$

\section{CONCLUSION}

This large population-based study provides strong evidence that CCB use is not associated with an increased risk of cancer when compared to no CCB use or other non-CCB AHT drugs. The analyses yielded results across all types of cancer and different durations of exposure to CCBs. It is likely that different results obtained from different countries are due to methodological rather than biological issues.

\section{Author affiliations}

${ }^{1}$ LA-SER, Paris, France

${ }^{2}$ Conservatoire national des arts et métiers (CNAM), Paris, France

${ }^{3}$ Utrecht Institute for Pharmaceutical Sciences, Utrecht University, Utrecht, The Netherlands

${ }^{4}$ European Medicines Agency, London, UK

${ }^{5}$ Pfizer Epidemiology, New York, New York, USA

${ }^{6}$ Tulane University, New Orleans, Louisiana, USA

${ }^{7}$ Department of Epidemiology, Biostatistics and Occupational Health, McGill University, Montreal, Canada

Contributors LG-B and OK drafted the protocol and the analyses plan and conducted the analyses. MR drafted the manuscript. LG-B supervised all operational aspects of the study including recruitment, data collection and management. All the authors made substantial contributions to conception or design of the work, reviewed the manuscript for important intellectual content, approved the final manuscript, and agreed to be accountable for all aspects of the work in ensuring that questions related to the accuracy or integrity of any part of the work are appropriately investigated and resolved.

Funding Innovative Medicine Initiative Joint Undertaking (http://www.imi. europa.eu). 
Disclaimer The views expressed in this article are the personal views of the authors and should not be understood or quoted as being made on behalf of or reflecting the position of their respective organisations.

Competing interests The PROTECT project has received support from the Innovative Medicine Initiative Joint Undertaking (http://www.imi.europa.eu) under Grant Agreement $n^{\circ} 115004$, resources of which are composed of financial contribution from the European Union's Seventh Framework Programme (FP7/2007-2013) and EFPIA (European Federation of Pharmaceutical Industries and Association) companies' in-kind contribution. LG-B is currently employed by LA-SER, the company conducting the study. OK reports having received a grant from IMI-PROTECT Consortium (http:// www.imi-protect.eu) during the conduct of the study. MCHdG reports having received a grant from IMI-PROTECT Consortium (http://www.imi-protect.eu) during the conduct of the study, and a grant from Top Institute Pharma (NL) (http://www.tipharma.com) outside the submitted work. ASMA reports having received a grant from IMI-PROTECT Consortium (http://www.imi-protect.eu) during the conduct of the study. MLdB reports having received a grant from IMI-PROTECT Consortium (http://www.imi-protect.eu) during the conduct of the study, and grants from TIPharma-Escher: Improving the EU system for marketing authorisation outside the submitted work. XK has no relationship with LA-SER that might have an interest in the submitted work in the previous 3 years. RR is an employee and shareholder of Pfizer, Inc; the views expressed are his and not necessarily those of Pfizer, Inc. LA-SER has no commercial interests in any of the products studied. Members of the LA-SER network have no interest in the drug or other factors studied. Private companies or agencies using PGRx for their studies obtain data by subscription. The authors consult or currently participate in studies sponsored by the following pharmaceutical companies: AstraZeneca, Boiron, Laboratoires Expanscience, Laboratoires Genevrier, GSK, Janssen-Cilag, Merck/Schering-Plough, Negma/Wockhardt, Novartis, Pfizer and several divisions of Sanofi.

Provenance and peer review Not commissioned; externally peer reviewed.

Data sharing statement No additional data are available.

Open Access This is an Open Access article distributed in accordance with the Creative Commons Attribution Non Commercial (CC BY-NC 4.0) license, which permits others to distribute, remix, adapt, build upon this work noncommercially, and license their derivative works on different terms, provided the original work is properly cited and the use is non-commercial. See: http:// creativecommons.org/licenses/by-nc/4.0/

\section{REFERENCES}

1. Li Cl, Daling JR, Tang MT, et al. Use of antihypertensive medications and breast cancer risk among women aged 55 to 74 years. JAMA Intern Med 2013;173:1629-37.

2. McManus RJ, Caulfield M, Williams B. National Institute for Health and Clinical Excellence. NICE hypertension guideline 2011: evidence based evolution. BMJ 2012;344:e181.

3. Daling JR. Calcium channel blockers and cancer: is an association biologically plausible? Am J Hypertens 1996;9:713-14.

4. Pahor M, Guralnik JM, Ferrucci L, et al. Calcium-channel blockade and incidence of cancer in aged populations. Lancet 1996;348:493-7.

5. Pahor M, Guralnik JM, Salive ME, et al. Do calcium channel blockers increase the risk of cancer? Am J Hypertens 1996;9:695-9.

6. Fitzpatrick AL, Daling JR, Furberg CD, et al. Use of calcium channel blockers and breast carcinoma risk in postmenopausal women. Cancer 1997;80:1438-47.

7. Largent JA, Bernstein L, Horn-Ross PL, et al. Hypertension, antihypertensive medication use, and breast cancer risk in the California Teachers Study cohort. Cancer Causes Control 2010;21:1615-24

8. $\mathrm{Li} \mathrm{Cl}$, Malone KE, Weiss NS, et al. Relation between use of antihypertensive medications and risk of breast carcinoma among women ages 65-79 years. Cancer 2003;98:1504-13.

9. Davis S, Mirick DK. Medication use and the risk of breast cancer. Eur J Epidemiol 2007;22:319-25.

10. Fryzek JP, Poulsen AH, Lipworth L, et al. A cohort study of antihypertensive medication use and breast cancer among Danish women. Breast Cancer Res Treat 2006;97:231-6.
11. Jick H, Jick S, Derby LE, et al. Calcium-channel blockers and risk of cancer. Lancet 1997;349:525-8.

12. Meier CR, Derby LE, Jick SS, et al. Angiotensin-converting enzyme inhibitors, calcium channel blockers, and breast cancer. Arch Intern Med 2000;160:349-53.

13. Michels KB, Rosner BA, Walker AM, et al. Calcium channel blockers, cancer incidence, and cancer mortality in a cohort of U.S. women: the nurses' health study. Cancer 1998;83:2003-7.

14. Perron L, Bairati I, Harel F, et al. Antihypertensive drug use and the risk of prostate cancer (Canada). Cancer Causes Control 2004;15:535-41.

15. Vezina RM, Lesko SM, Rosenberg L, et al. Calcium channel blocker use and the risk of prostate cancer. Am J Hypertens 1998;11:1420-5.

16. Hall GC, Sauer B, Bourke A, et al. Guidelines for good database selection and use in pharmacoepidemiology research. Pharmacoepidemiol Drug Saf 2012;21:1-10.

17. Abbing-Karahagopian V, Kurz X, de Vries F, et al. Bridging differences in outcomes of pharmacoepidemiological studies: design and first results of the PROTECT project. Curr Clin Pharmacol 2014:9:130-8.

18. Herrett E, Thomas SL, Schoonen WM, et al. Validation and validity of diagnoses in the General Practice Research Database: a systematic review. Br J Clin Pharmacol 2010;69:4-14.

19. Nielen MM, Ursum J, Schellevis FG, et al. The validity of the diagnosis of inflammatory arthritis in a large population-based primary care database. BMC Fam Pract 2013;14:79.

20. Tannen RL, Weiner MG, Xie D. Use of primary care electronic medical record database in drug efficacy research on cardiovascular outcomes: comparison of database and randomised controlled trial findings. BMJ 2009;338:b81.

21. Shah AD, Martinez C. An algorithm to derive a numerical daily dose from unstructured text dosage instructions. Pharmacoepidemiol Drug Saf 2006;15:161-6.

22. Van Staa TP, Abenhaim L, Cooper C, et al. The use of a large pharmacoepidemiological database to study exposure to oral corticosteroids and risk of fractures: validation of study population and results. Pharmacoepidemiol Drug Saf 2000;9:359-6.

23. Lei J, Sockolow P, Guan P, et al. A comparison of electronic health records at two major Peking University Hospitals in China to United States meaningful use objectives. BMC Med Inform Decis Mak 2013;13:96.

24. Beiderbeck-Noll $A B$, Sturkenboom MC, van der Linden PD, et al. Verapamil is associated with an increased risk of cancer in the elderly: the Rotterdam study. Eur J Cancer 2003;39:98-105.

25. Pahor M, Furberg CD. Is the use of some calcium antagonists linked to cancer? Evidence from recent observational studies. Drugs Aging 1998:13:99-108.

26. Jick $\mathrm{H}$. Calcium-channel blockers and risk of cancer. Lancet 1997;349:1699-700.

27. Rosenberg L, Rao RS, Palmer JR, et al. Calcium channel blockers and the risk of cancer. JAMA 1998;279:1000-4

28. Stahl M, Bulpitt CJ, Palmer AJ, et al. Calcium channel blockers, ACE inhibitors, and the risk of cancer in hypertensive patients: a report from the Department of Health Hypertension Care Computing Project (DHCCP). J Hum Hypertens 2000;14:299-304.

29. Boudreau DM, Koehler E, Rulyak SJ, et al. Cardiovascular medication use and risk for colorectal cancer. Cancer Epidemiol Biomarkers Prev 2008;17:3076-80.

30. Bergman GJ, Khan S, Danielsson B, et al. Breast cancer risk and use of calcium channel blockers using Swedish population registries. JAMA Intern Med 2014;174:1700-1.

31. Olsen $\mathrm{JH}$, Sorensen HT, Friis $\mathrm{S}$, et al. Cancer risk in users of calcium channel blockers. Hypertension 1997;29:1091-4.

32. Sørensen HT, Olsen JH, Mellemkjaer L, et al. Cancer risk and mortality in users of calcium channel blockers. A cohort study. Cancer 2000;89:165-70.

33. Cohen HJ, Pieper CF, Hanlon JT, et al. Calcium channel blockers and cancer. Am J Med 2000;108:210-15.

34. González-Pérez A, Ronquist G, Garcia Rodriguez LA. Breast cancer incidence and use of antihypertensive medication in women. Pharmacoepidemiol Drug Saf 2004;13:581-5.

35. Trenkwalder $P$, Hendricks $P$, Hense HW. Treatment with calcium antagonists does not increase the risk of fatal or non-fatal cancer in an elderly mid-European population: results from STEPHY II. Starnberg Study on Epidemiology of Parkinsonism and Hypertension in the Elderly. J Hypertens 1998;16:1113-16. 